SUCCESSFUL REMOVAL OF IHE UTERUS BY LIGATURE.

By Jonathan Toogood, M D., Bridgewater.

The following case, although not similar to that published by Mr. Crosse, in the Jonrnal of the 12th of June, atfords an additional example of the safety and propriety of removing the uterus under certain circumstances.

About sixteen years ago I was requested to visit Miss L., aged about forty, who was represented to be suffering from a considerable swelling, which prevented her from passing any water. The introduction of the catheter was rendered somewhat dificult from the protrusion of a large mass from the vagina, but after a little time I succeeded in drawing off between two and three pints of water, and then proceeded to make a more accurate examination. I found that the uterus was completely prolapsed, and hanging down between the thighs. There was not much difficulty in returning it, or retaining it in its natural situation by a large globular India-rubber pessary, which I directed to be remored occasionally and replaced. I heard nothing more of my patient for three years, when I was again desired to see her on account of a profuse and most offensive discharge, which had existed for some time. To my very great surprise I discovered that the pessary had never been removed, which at once explained the cause, and I was actually obliged to deliver her of it with the forceps. From that time, as I subsequently learn. it was nerer replaced, consequently, the uteris was ternently coming down, and prolapsing beyond tie external parts, and she had acquired the habit of returning it by sitting over an open space, and pushing it back with her fingers. This course was pursued until the 13th of April last, when it came down, and, after making repeated ineffcctual attempts to return it for three days, she sent for mylate partner, Mr. Parsons, who gives me the following statement:

"On Wednesday, April 17th, I was sent for to see Miss L., a maiden latly, nearly sixty years old, who I had before known to have been suffering from a prolapsus of the womb; on my arrival I was informed that this had come down on the Saturday previously; during a riolent fit of coughing, and that all her attempts to reduce it, had failed. On examination I discovered a very large protrusion of a pyriform shape, and extending from the vagina to at least seven or eight inches. The surface was not very sensitive, but was of a red, florid colour, and in some parts ulcerated and ecchymosed from repeated attempts to effect its reduction, and from which some hæmorrhage occasionally occurre?. Every endeavour on my part to return it being fruitless, I ordered some leeches and cold applications to be used, hoping, in a day or two, by these means, to reduce its bulk, so as to enable me to return it. None of these remedies, however, succeeded, and as, on a more careful examination, I discovered that the neck of this large inass, as it entered the vagina, rather diminished in size, I requested a consultation with my friend Dr. Toogood, who had formerly attended the patient, who agreed with me on the practicability and safety of removing the whole by ligature. Accordingly, on Sunday the 21st, we applied a ligature very firmly round the neck of the swelling, just within the vagina, and took away the protruded part immediately.
"The mass removed was about two pounds weight, the shape of the uterus, but its structure much altered in character, the cavity being quite obliterated, and the os uteri become almost cartilaginous. No bad symptoms ensued, and she told me yesterday, the 22 nd, that she was as well as when she was sixteen.

"On examination, no uterus can be discovered, but the vagina seems to terminate in a short cul de sac."

At the time I met Mr. Parsons in consultation, the patient was in a very suffering state from general irritation and repeated discharges of blood, and as the parts had begun to assume a somewhat flaccid and livid appearance, I thought the safest course would be to remove the whole as speedily as possible, and I advised the operation with the greater confidence, from having, in the course of my experience, known two other cases in which the whole body of the uterus was removed by ligature, without any immediate danger; but as these cases were not my own, I know nothing of the details or ultimate event of either.

Bridgewater, June 24, 1844.

\section{CASE OF PERITONEAL DROPSY.}

By Edward Daxirlu, Esq., Newport Pagnell.

In offering the following case to the profession, $I$ ain aware that $I$ am adding but very little to the general stock of knowledge in peritoneal dropsy, but as the case was successful, and that after only one operation, I thought the particulars of it would not be unacceptable, for to practical men one fact is of more value than a thousand suggestions.

, 37 years of age, was delivered on the 3 rd of April, 1835, of her fiftl child; the case was simple, and the labour not protracted; a month passed on without any symptom of an unpleasant character. She was enabled to pay several friendly visits to ladies who had faroured her with kind enquiries during her confinement, and on one of these visits was overtaken by a shower, which made her damp and uncomfortable, but anticipating no evil, she did not regard it. She was however seized on the following day with severe pain over the whole abdomen, which seemed at length to concentrate itself in the left groin. The pain was so intolerable that she could not stand erect, and there was tenderness on pressure, costiveness, and pyrexia, symptoms clearly indicating inflammation of the peritoneum.

She was bled in the arm, leeched, cupped, and blistered, and, as the attack was combined with considerable cerebral disturbance, her hair was close cut off, spirit lotions applied to the head, and the general antiphlogistic plan pursued. By this process the inflammatory symptoms gave way, but they were only yielding to exhibit another form of disorder, too common where membranes analogous to the peritoneum, are the seat of active mischief.

Tumefaction of the abdomen became visible in a week after the inflammatory symptoms had subsided, fluctuation was perceptible, and I need not add, that from the obstinate nature of such cases generally, the final result was referred to with very gloomy anticipations.

Sn:all and repeated doses of mercury were given without any obvious effect upon the system; ptyalism could not be induced; elaterium in its usual forms was administered, and neutral diuretic salts combined 
with erery agent generally employed to rouse the torpid condition of the kidneys, but without effect. Recourse was then had to small and repeated doses of iodide of potassium, and an ointment compounded of the same salt was directed to be rubbed freely over the abdominal region. The effect of this ointment was to produce extensive cutaneous irritation, and the tenderness was so great, that the patient begged to have it laid aside. It was, however, repeatedly used when the condition of the skin would permit it. In spite of these measures the accumulation gained ground; the patient became cachectic, and so exceedingly reduced in flesh, that it became obvious that she would sink, if the disorder could not be orercome by other means, than those hitherto employed.

I therefore proposed an operation, being convinced that if any good was to be derived from removing the accumulation by such process, it would be better to do it without the least delay.

I consulted my friend, Dr. R. on the subject, who bestowed much pains in considering the case; he thought with me that it would not be possible to avoid an operation, but suggested a plan of treatment which might have a fortnight's trial, and then if no good resulted, to proceed at once to paracentesis abdominis.

The medicine, however, produced no effect; it did not even stimulate the kidnies to more activity than what had been done previously, while the accumulation was increasing daily, and the distention of the abdomen distressing. Therefore, on the 17 th of June, just eight days after Dr. R. had seen her, and six weeks from the commencement of the attack, I performed the operation, assisted by $\mathrm{my}$ excellent friend, $\mathrm{Mr}$. Rogers, of this town, when fourteen pints of dark coloured fluid, resembling in appearance water, in which aloes and saffron were infused, were abstracted. The patient bore the operation well, the abdomen was well bandaged; she was put to bed, and from that time to her perfect recovery, not one important symptom occurred. She has since had two other children, and with the exception of occasional constipation, which indeed has always been her peculiar habit, she enjoys at this time perfect health. The secretion of milk, which was scanty during her illness, became most abundant after her recovery, and she was enabled to suckle her infant her usual time.

Remarks:-This case has suggested to me one material point in the treatment of peritoneal dropsy, viz., not to uselessly protract an operation. Effusion may be considered as one of the accidents of inflammation, and occurs without any hydropic disposition; but if water be suffered to remain for months in the cavity of the abdomen, vitiating and emasculating the bowels, and weakening the energy of the absorbent vessels, it appears obvious the accumulation will return, and an hydropic diathesis be induced. I am also inclined to think that the previous medical treatment had its share in this successful recovery, for although the mercury and iodine were incapable of exercising an influence on the vast body of water deposited, who shall say that when that water was removed they were not active agents in preventing a return?

Newport Pagnell, Bucks, June 25, 1844.
CASE OF TWINS, IN WHICH THE PLACENTA OF THE FIRST CHILD WAS NEARLY DE. TACHED, BEFORE THE MEMBRANES OF THE SECOND WERE RUPTURED.

TO THE EDITOR OF THE PROVINCIAL MEDICAL AND SIR, SURGICAL JOURNAL.

There is not anything new either in the following case, or the treatment of it, but perhaps it might bave been managed better; and if so, my want of due care on the occasion may be a caution to others who meet with similar cases; for it is easier to see afterwards what might have been done, than to do everythin: well at the time of such an occurrence. From these considerations I send the case for your decision, whether or not the publication of it may be desirable, renaining, Sir, Yours respectfully, W. ALLISON

East Retford, June 24, 1844.

I was requested on the 24 th of May, 1844, to see a woman, (the wife of a butcher, named Hawksley,) who was supposed to be in labour of her fourth child and who had suffered from frequent uterine pains which had prevented her from sleeping during the last twenty-four hours. 'The child's head was felt presenting at the brim of the pelvis; not pressing upon the lower part of the uterus, round the os uteri; the os uteri nearly as large as a half-crown piece; the membranes neither broken nor protruding. There was a coloured though not excessive discharge. She was desired to get into bed, and to take some gruel, which was not to be hot.

On calling again after a lapse of some hours, the membranes were rather protruding, but the pains were still inefficient. The woman told me that one of her intimate friends had remarked that day, "From your size, you do not appear to me to be at your full time;" and she named that remark to me, just at the moment when I was thinking that the uterus was over distended, and more probably so by two childrea than by an unusual quantity of liquor amnii. $\mathrm{O}_{\mathrm{a}}$ examining her body externally, it felt large at the sides, and as if the uterus contained twins.

As the edge of the os uteri had becone thinner, the membranes were ruptured, and in about one hour it child was expelled; the navel-string was tied and cut, when the untied end bled so freely as to require a ligature. On passing a finger along the cord, about half the placenta was felt in the vagina; as, however, the abdomen was not much less in size, I made my left arm bare and passed my hand beyond the placenta into the uterus; when feeling a second head, I again ruptured the membranes, and then feeling what I thought was a knee, pulled it down, and found $a$ hand in the vagina. Having returned my hand, having found two knees, and having ascertiined that they belonged to one child; I used a good deal of force in turning the child with its legs downwards, the disturbance of which, produced some pains, and a second child was soon expelled, bringing the first placenta before it. There was profuse hæmorrhage during the extraction of the second child. The other placenta was readily peeled off, from the fundus of the uterus, and was 